\title{
The Molybdenum Site of Nitrogenase. Preliminary Structural Evidence from X-Ray Absorption Spectroscopy
}

\author{
Stephen P. Cramer, ${ }^{1 a}$ Keith O. Hodgson, ${ }^{1 a}$ William O. Gillum, ${ }^{1 a}$ and \\ Leonard E. Mortenson ${ }^{1 b}$ \\ Contribution from the Department of Chemistry. Stanford University, \\ Stanford, California 94305, and the Department of Biological Sciences, Purdue University, \\ Lafayette, Indiana 47907. Received September 13, 1977
}

\begin{abstract}
One of the two protein components of the nitrogenase enzyme system (the so-called MoFe protein) contains two Mo atoms and 24-32 Fe atoms per 220-270 000 molecular weight. Despite many hypotheses about the Mo site and its involvement in dinitrogen reduction, there has been no spectroscopic means of unambiguously probing the state of Mo. In this paper, the results of $\mathrm{x}$-ray absorption spectroscopy studies are described and the analysis of these results provides the first direct evidence of the Mo coordination environment in the MoFe protein from Clostridium pasteurianum nitrogenase. The Mo is found to have primarily S ligation and in the resting state ("semireduced form") of the protein there appears to be no Mo=O species present. On air oxidation, however, clear evidence is found for the presence of $\mathrm{Mo}=\mathrm{O}$. The interaction of the Mo with one other metal, most probably $\mathrm{Fe}$ and most certainly not $\mathrm{Mo}$, is also seen and it is suggested that the Mo is present in a $\mathrm{Mo}-\mathrm{Fe}-\mathrm{S}$ cluster not yet adequately modeled by any synthetic inorganic system.
\end{abstract}

\section{Introduction}

The molybdenum-iron (MoFe) protein of Clostridium pasteurianum nitrogenase contains two molybdenum atoms and approximately 24 atoms each of iron and acid-labile sulfide per molecular weight of 220000 . $^{2 a}$ Despite many hypotheses that molybdenum is at the site of dinitrogen reduction, ${ }^{2 b}$ until recently there has been no unambiguous means of spectroscopically monitoring the state of molybdenum in this protein. The UV-visible absorption spectrum of the MoFe protein is a featureless, monotonic rise in absorbance from $700 \mathrm{~nm}$ to the ultraviolet, ${ }^{3}$ and the $\mathrm{MCD}$ and $\mathrm{CD}$ spectra in this region are also uninformative. ${ }^{3,4}$ The low-temperature EPR spectrum of the clostridial MoFe protein as isolated (the so-called "semireduced" form) has resonances at $g=4.27,3.78$, and 2.01 , and these have been attributed to a spin $3 / 2$ system with rhombic and axial distortion. ${ }^{5}$ The EPR of the MoFe protein of Klebsiella pneumoniae grown on $87 \%{ }^{57} \mathrm{Fe}$ shows about a $5-\mathrm{G}$ broadening of the sharpest resonance, ${ }^{6}$ but no hyperfine interaction is observed upon incorporation of ${ }^{95} \mathrm{Mo}$ into the MoFe protein. ${ }^{6}$ Similar results were obtained with isotopically labeled Azotobacter vinelandii MoFe protein. ${ }^{7}$ Although these experiments are consistent with the presence of $\mathrm{Fe}$ at the EPR-active site, the absence of a measurable effect with ${ }^{95} \mathrm{Mo}$ does not eliminate the presence of an EPR-silent Mo at this site. ${ }^{8}$ The paucity of information about the Mo in nitrogenase is such that, until recently, the only evidence for its presence came from elemental analysis of the MoFe protein and the nutritional requirement for Mo in nitrogen fixation. ${ }^{9}$ There is obviously a great need for a spectroscopic method which can define the state of Mo in nitrogenase.

$\mathrm{X}$-ray absorption spectroscopy is one technique which can unambiguously examine a particular element in a complex sample in any physical state. The availability of a high-intensity, broad-band synchrotron radiation source at Stanford has made data collection on dilute samples such as metalloproteins feasible for the first time, and reports have been published on the spectra of iron- ${ }^{10}$ and copper-containing proteins. ${ }^{11}$ In this paper, Mo K-edge x-ray absorption spectra of the Clostridial MoFe protein are presented and analyzed. These results will expand upon previously reported edge data ${ }^{12}$ and present, for the first time, conclusive information about the Mo environment. The EXAFS data provide clear evidence for primarily sulfur ligation to molybdenum, and together with the edge data they conclusively rule out the presence of "doubly bound" oxygen(s). ${ }^{13}$ It is suggested that the molybdenum in nitroge- nase is present in a Mo-Fe-S "cluster" of a type not yet adequately modeled by any synthetic inorganic system.

\section{Experimental Section}

Protein Purification and Lyophilization. The MoFe and Fe proteins of Clostridium pasteurianum were prepared by the method of Zumft and Mortenson. ${ }^{14}$ Techniques used to analyze for protein, $\mathrm{Mo}, \mathrm{Fe}, \mathrm{S}^{2-}$, and activity are also cited in ref 14 . In order to obtain the best possible EXAFS data, a sample with the concentration of Mo as high as possible was required. Since the highest $\mathrm{MoFe}$ protein concentration that can be obtained in solution is ca. $200 \mathrm{mg} / \mathrm{mL}$ or about $2 \mathrm{mM} \mathrm{Mo}$, and since data with the best possible $\mathrm{S} / \mathrm{N}$ ratio were desired, lyophilized samples were prepared for these preliminary studies. For lyophilization, $3 \mathrm{~mL}$ of a $70 \mathrm{mg} / \mathrm{mL}$ sample of the MoFe protein with activity of $1.5 \mu \mathrm{mol}$ acetylene reduced $\mathrm{min}^{-1} \mathrm{mg}^{-1}$ protein was pipetted anaerobically under argon into a $50-\mathrm{mL}$ lyophilizing flask. The preparation was shell frozen on the inside of the flask and the flask immediately attached to the lyophilizer and evacuated. To further protect against oxidation during lyophilization, $0.1 \mathrm{mM}$ sodium dithionite was added to the preparation before freezing. Once dried, the lyophilized powder (ca. $200 \mathrm{mg}$ of protein containing $1.7 \mu \mathrm{mol}$ of $\mathrm{Mo}$ ) was packed into a Lucite block designed for the $\mathrm{x}$-ray absorption analysis. All transfers were made in a moisture-free box under argon. After transfer the open end of the block was sealed with a piece of Lucite fixed to the block by epoxy glue.

After the sample was analyzed, the block was opened under moisture-free conditions and the powder transferred to a dry tube. The tube was sealed with a serum stopper, the gas phase in the tube was changed to argon, and $5 \mathrm{~mL}$ of $\mathrm{O}_{2}$-free deionized water was added anaerobically by syringe. This solution of MoFe protein when assayed had an activity of $1.3 \mu \mathrm{mol}$ acetylene reduced $\mathrm{min}^{-1} \mathrm{mg}^{-1}$ protein. This compares favorably with the initial activity of 1.5 ( $87 \%$ recovery).

Preparation of Dye-Oxidized, Full Reduced, and Air-Oxidized States. It has been previously shown that the MoFe protein could exist in three states-the dye-oxidized, the semireduced, and the full reduced-all of which can be fully activated in the nitrogenase assay. $5.15,16$ The lyophilized preparation described above was in the semireduced state. In a prior publication, edge data were reported on a lyophilized sample which had been partially air oxidized. ${ }^{12}$ For the experiments to be described in this paper, the fully reduced and dyeoxidized forms of the MoFe protein were also prepared in conjunction with semireduced solution and lyophilized samples.

The dye-oxidized form was prepared by adding anaerobically an amount of a concentrated, $\mathrm{O}_{2}$-free solution of oxidized dye, thionine (Lauth's violet), to the semireduced form. The amount of dye added was equivalent in molar concentration to the MoFe protein plus enough dye to oxidize the traces of dithionite in the preparation. ${ }^{15}$ For 
each milliliter of a preparation of dithionite-free MoFe protein of 88 $\mathrm{mg} / \mathrm{mL}, 0.8 \mu \mathrm{mol}$ of thionine was added in as small a volume as possible so that the Mo concentration would not be diluted significantly. The resulting oxidized MoFe sample, which exhibited less than $10 \%$ of the original EPR signal, was examined as a solution frozen at dry ice temperature.

The preparation of the fully reduced form was more complicated since semireduced MoFe protein can only be reduced effectively by electrons supplied by the Fe protein. ${ }^{15}$ In addition, the electron transfer requires and utilizes adenosine triphosphate. For this experiment the following solutions were prepared and made anaerobic: MoFe protein, $0.44 \mu \mathrm{mol} / \mathrm{mL}$ containing $1.7 \mathrm{Mo}$ atoms $/ \mu \mathrm{mol}$; Fe protein, 0.4 $\mu \mathrm{mol} / \mathrm{mL}$ containing $3.7 \mathrm{Fe}$ atoms $/ \mu \mathrm{mol}$; an ATP-generating system containing (per $0.1 \mathrm{~mL}$ ) 105 units of creatine kinase, $8 \mu \mathrm{mol}$ of ATP, $20 \mu \mathrm{mol}$ of $\mathrm{Mg}^{2+}$, and $10 \mu \mathrm{mol}$ of creatine phosphate added to $1 \mathrm{M}$ Tris- $\mathrm{HCl}$ at $\mathrm{pH} 8.0$ (final $\mathrm{pH} 7.8$ ); and $\mathrm{Na}_{2} \mathrm{~S}_{2} \mathrm{O}_{4}, 100 \mu \mathrm{mol} / \mathrm{mL}$ in $0.5 \mathrm{M}$ Tris $-\mathrm{HCl}(\mathrm{pH} 8.0)$. For preparation of fully reduced $\mathrm{MoFe}$ protein $1.2 \mathrm{~mL}$ of MoFe protein was mixed anaerobically with $0.1 \mathrm{~mL}$ of $\mathrm{Na}_{2} \mathrm{~S}_{2} \mathrm{O}_{4}$ in a $5-\mathrm{mL}$ vial sealed with a serum cap. Using a syringe, $0.13 \mathrm{~mL}$ of the ATP-generating system was added to the MoFe protein/dithionite solution. After mixing and checking that dithionite was in excess and that the $\mathrm{pH}$ was $7.8,0.13 \mathrm{~mL}$ of Fe protein solution was added. This reaction mixture (under argon) was mixed for $2 \mathrm{~min}$ at $25^{\circ} \mathrm{C}$ after which time $1 \mathrm{~mL}$ was transferred rapidly and anaerobically into an anaerobic EXAFS cell and $0.3 \mathrm{~mL}$ into an anaerobic EPR tube. For comparison purposes, $0.23 \mathrm{~mL}$ of MoFe protein and $0.07 \mathrm{~mL}$ of $0.05 \mathrm{M}$ Tris- $\mathrm{HCl}$ ( $\mathrm{pH} 8.0$ ) were added to a second EPR tube. All samples were immediately frozen in either dry ice or liquid $\mathrm{N}_{2}$. On examination, the control tube with the semireduced $\mathrm{MoFe}$ protein had the expected EPR signal with $g$ values of $4.27,3.78$, and 2.01. The fully reduced sample had, as expected, less than $5 \%$ of this EPR signal. ${ }^{17,18}$

Air-oxidized samples were prepared by redissolving the lyophilized material in a minimal amount of aerated $50 \mathrm{mM} \mathrm{pH} \mathrm{7.4} \mathrm{Tris} \mathrm{buffer.}$ Bubbling began almost immediately, and the odor of $\mathrm{H}_{2} \mathrm{~S}$ was quite apparent. The first spectrum of this material was recorded about 2 $\mathrm{h}$ later. After $6 \mathrm{~h}$ of room temperature data collection, the sample was returned to $4{ }^{\circ} \mathrm{C}$ for storage. After 2 weeks of storage, the sample's spectrum was again recorded.

X-Ray Absorption Measurements. The X-ray absorption spectra of all samples were obtained at the Stanford Synchrotron Radiation Laboratory (SSRL) using a Si $[2,2,0]$ channel cut crystal monochromator ${ }^{19}$ and argon-filled ionization detectors. The instrumental resolution was better than $6 \mathrm{eV}$ (estimated from the fwhm of the sharpest feature in the $\mathrm{MoO}_{4}{ }^{2-}$ edge). The photon flux available after monochromatization was a strong function of the electron storage ring operating conditions; for example, at $3.48 \mathrm{GeV}$ and $31 \mathrm{~mA}$, the available flux was about $10^{9}$ photons $/ \mathrm{s}$ in a $1 \times 20 \mathrm{~mm}$ area at $20 \mathrm{keV}$, while at $2.71 \mathrm{GeV}$ and $14.2 \mathrm{~mA}$ the flux was about $3 \times 10^{7}$ photons $/ \mathrm{s}$. All of the protein spectra were recorded when the ring was at $3.2 \mathrm{GeV}$ or higher.

The absorption spectra were calibrated with respect to the absorption edge of Mo foil, using the first inflection point of the foil edge as $20003.9 \mathrm{eV} .{ }^{20}$ The first and second derivatives of all edges were calculated using sequential applications of a cubic finite difference approximation over a 7-eV interval. Long-term reproducibility of inflection point measurements on standard samples was better than $\pm 0.75 \mathrm{eV}$. The data processing required for the analysis of the EXAFS data has been previously described in detail. ${ }^{21}$

The sample cells were Lucite blocks in which a channel was machined to hold the protein. The path length was $20 \mathrm{~mm}$ and channel dimensions perpendicular to the beam were $2 \times 25 \mathrm{~mm}$. The cell windows were made of $1.6 \mathrm{~mm}$ thick Lucite. Solid samples were packed into the cell in an anaerobic glove box, while solutions were injected anaerobically with a gas-tight syringe through a rubber septum in a glass tube at the top of the cell. The solution samples were kept frozen in a Styrofoam box packed with dry ice while the spectra were being recorded.

The spectrum of the lyophilized material was recorded on two separate occasions using two different protein samples and averaged. The EXAFS presented represents about $15 \mathrm{~h}$ of actual data collection over a $1000-\mathrm{eV}$ region; it is actually the sum of about 30 individual 30-min scans. The solution absorption edges each required about 2 h of data collection over a 100-eV region. The actual "hands-on" instrumental time required to obtain useful spectra was generally a factor of 2 or 3 greater than the data collection time.

\section{Results}

The Mo K-edge x-ray absorption spectrum of Clostridial MoFe protein can be divided into two distinct regions: (1) the absorption edge-whose shape and position contain information about the type(s) of ligands, the coordination geometry (site symmetry), and possibly the metal oxidation state, ${ }^{22,25}$ and (2) the extended x-ray absorption fine structure (EXAFS) - which can reveal the type, number, and distances of neighboring atoms. ${ }^{21}$ It was relatively easy to obtain useful Mo absorption edge data on several different states of the $\mathrm{MoFe}$ protein in solution. On the other hand, collection and analysis of EXAFS data required a much better signal to noise ratio, since oscillations with amplitudes typically from 10 to $0.1 \%$ the size of the edge jump were being measured. Therefore, the EXAFS of the MoFe protein has been initially recorded using a lyophilized powder. This was done to minimize solvent background absorption and to obtain the highest possible fraction of absorption by Mo. For the lyophilized protein, the Mo contributes about $10 \%$ of the total absorption, while in solutions with $100 \mathrm{mg} / \mathrm{mL}$ of protein (about $1 \mathrm{mM}$ in Mo) the Mo absorption is only about $1 \%$ of the total. The edges recorded from solution samples and the EXAFS data from a lyophilized sample will be presented separately, and the combined evidence will be used to discuss the structure of the Mo site.

The Mo K Absorption Edge Region. In the metal $\mathrm{K}$ absorption edge region of coordination complexes, one typically observes a series of discrete spectral peaks (due to transitions of the $1 \mathrm{~s}$ electron to unoccupied molecular orbitals of metal character) superimposed upon a steeply rising absorption trend (due to transitions of the 1 s electron into continuum levels). ${ }^{23}$ The shape of the edge, which is determined by the relative intensities and widths of these low-lying "bound-state" transitions, contains information about the geometry of the metal complex and the nature of the ligands present. Thus, octahedral complexes of first-row transition metals with relatively hard ligands (amines, waters, halides, etc.) have strong $1 \mathrm{~s}-4 \mathrm{p}$ transitions, but very weak $1 \mathrm{~s}-3 \mathrm{~d}$ and $1 \mathrm{~s}-4 \mathrm{~s}$ transitions. ${ }^{24} \mathrm{On}$ the other hand, complexes with tetrahedral geometry have strongly enhanced $1 \mathrm{~s}-n \mathrm{~d}$ and $1 \mathrm{~s}-(n+1)$ transitions, because of a mixing of $d, s$, and $p$ character in the excited state orbital. ${ }^{11 \mathrm{a}, 24}$ Finally, ligands which have multiple-bonding interactions with the metal can intensify either the $1 \mathrm{~s}-n \mathrm{~d}$ or the 1s $-(n+1)$ s transitions or both. 25

The positions of the absorption edge features are sensitive to the metal oxidation state and environment. As the electronegativity of the ligands increases, the edge features move to higher energy. ${ }^{12}$ Furthermore, for a given set of ligands, the edge moves to higher energy as the metal oxidation state increases. This shift can be as large as $5 \mathrm{eV}$ per unit oxidation state change (as with highly ionic fluorides). ${ }^{24}$ It is typically about $2 \mathrm{eV}$ for oxides and chlorides ${ }^{12}$ and about $1 \mathrm{eV}$ or less per oxidation state change with highly polarizable ligands (as with cyanides ${ }^{24}$ and sulfur-containing ligands ${ }^{22,25}$ ). Systematic trends in the absorption edges of molybdenum compounds have been discussed in detail elsewhere. 22,25

Several distinct states of the MoFe protein have been characterized by EPR spectroscopy, and the Mo absorption edges of four of these states have been investigated to see whether changes in the overall protein oxidation level can be related to changes in the Mo oxidation state. The Clostridial $\mathrm{MoFe}$ protein, as isolated in the presence of dithionite, exhibits an EPR with $g$ values of $4.27,3.78$, and $2.01 .^{5}$ This state is termed "semireduced" (or Cpl ${ }^{\text {sr }}$ ), since the EPR can be eliminated by further reduction with dithionite, Fe protein, and MgATP (to yield the "fully reduced", Cpl ${ }^{\mathrm{fr}}$, state) or by oxidation with thionine or methylene blue (to yield the "dyeoxidized", $\mathrm{Cpl}{ }^{\mathrm{do}}$, state). Finally, the protein can be irreversibly 


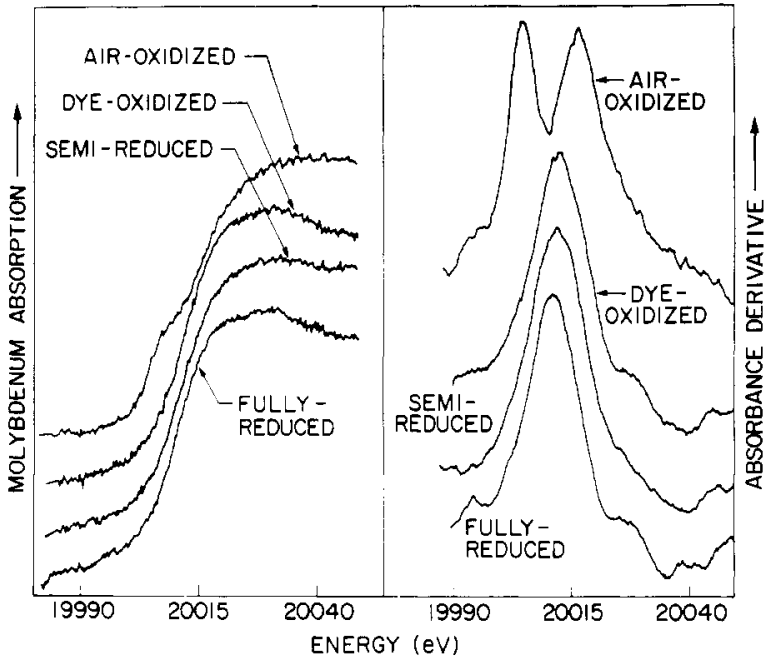

Figure 1. Molybdenum $\mathrm{K}$ x-ray absorption edges of Clostridial MoFe protein in four different states. For these solution spectra, the total absorption is dominated by water absorption $(90 \%)$, protein absorption $(6 \%)$, and $\mathrm{Fe}-\mathrm{S}$ absorption (3\%). These components decrease monotonically as the photon energy increases, giving rise to a sloping background on which the Mo K-edge is superimposed (see Figure 2 of ref 12). The Mo component was removed from the background absorption by fitting a straight line to the total absorption on the range of 19930 to $19990 \mathrm{eV}$, and subtracting this line from the total absorption. Since the extracted Mo absorption peak positions are sensitive to the slope of the subtracted preedge, small differences in peak positions on the order of $1 \mathrm{eV}$, as measured by changes in the inflection points, are not necessarily significant (see Experimental Section). The derivative spectra (right) are useful because (a) they are much less sensitive to background absorption and (b) they help sharpen the rather broad features common to most Mo edges. The absorption derivatives were calculated using a cubic finite difference approximation over a $7-\mathrm{eV}$ ( 26 data point) interval.

Table I. Absorption Edge Information

\begin{tabular}{clcc}
\hline State & \multicolumn{1}{c}{ Conditions } & Inflection point(s) & Peak \\
\hline Fully reduced & Solution (a) & 20011.1 & 20030.9 \\
& Solution (b) & 20011.6 & 20032.1 \\
& Solution (c) & 20011.7 & 20030.7 \\
Semireduced & Lyophilized (a) & 20011.5 & 20024.5 \\
& Solution (b) & 20012.1 & 20033.5 \\
Dye oxidized & Solution & 20012.5 & 20031.8 \\
Air oxidized & Solution (a) & $20004.9,20014.9$ & 20042.1 \\
& Solution (b) & $20004.9,20016.6$ & 20041.8 \\
\hline
\end{tabular}

oxidized by exposure to air or $\mathrm{O}_{2}$ (to yield the "air-oxidized", $\mathrm{Cpl}^{\mathrm{aoo}}$, state(s)), in which case a complicated EPR spectrum results. ${ }^{5}$ The Mo $\mathrm{K}$ absorption edges for these four states are presented in Figure 1, and the relevant inflection point and peak energies are listed in Table I.

The semireduced state of Clostridial MoFe protein, $\mathrm{Cp}^{\mathrm{sr}}$, has a smooth, featureless absorption edge, whether the protein is lyophilized or in solution (see Figure 2), and the derivative spectrum reveals single peaks at 20011.5 and $20012.1 \mathrm{eV}$, respectively. Although the slopes of the edges appear to differ in the region beyond $20020 \mathrm{eV}$, this is more likely an artifact of the procedure for removing the background absorption than a real difference in the spectra. The similarity in the shape and peak positions of the derivative spectra leads to the conclusion that no drastic changes in the Mo coordination sphere occur upon lyophilization.

In order to make some structural conclusions from the shape and position of the $\mathrm{Cpl}^{\mathrm{sr}}$ edges, it has been assumed that the biochemically reasonable ligand possibilities for $\mathrm{Cpl}^{\text {sr }} \mathrm{Mo}$ involve nitrogen, oxygen, or sulfur coordination, and that the reasonable $\mathrm{Mo}$ oxidation states are $\mathrm{Mo}^{\mathrm{III}}-\mathrm{Mo}^{\mathrm{VI}}$. Comparison of the $\mathrm{Cpl}^{\mathrm{sr}}$ edge with those of known compounds (see Table

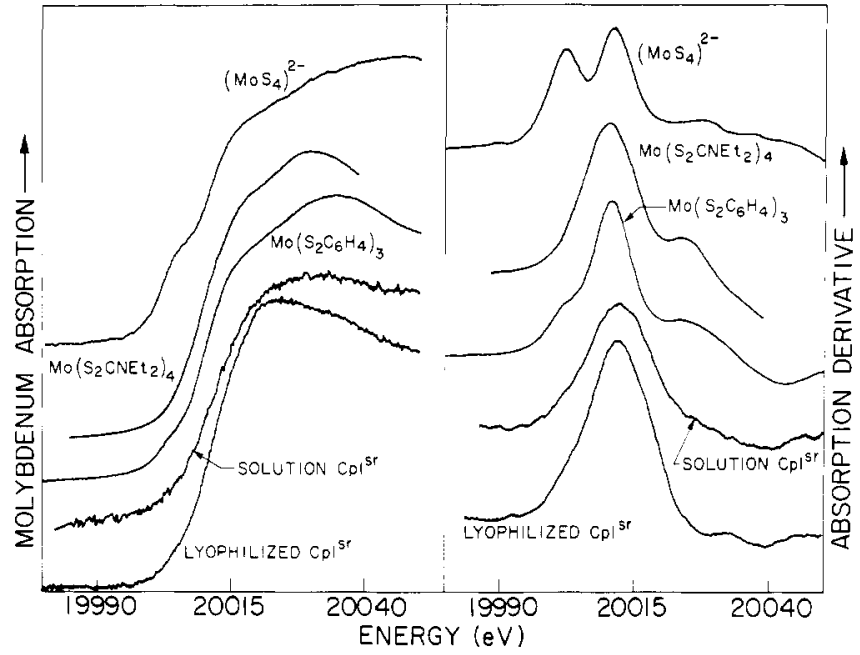

Figure 2. A comparison of lyophilized and solution $C \mathrm{p}^{\mathrm{s} r}$ with three molybdenum compounds with all-sulfur coordination. The two edge inflection points for $\left(\mathrm{MoS}_{4}\right)^{2-}$ are 20000.1 and $20010.0 \mathrm{eV}$ and the single edge inflection point for the other edges (top to bottom) are $20010.0,20010.5$. 20011.5 , and $20012.2 \mathrm{eV}$. Data processing was similar to that of Figure 1 , except that the model compounds did not require a preedge background subtraction. Note that the $1 \mathrm{~s}-4 \mathrm{~d}$ transition is extremely weak except in the case of tetrahedral coordination for $\mathrm{Mo}$ in $\left(\mathrm{MoS}_{4}\right)^{2-}$.

Table II. Relevant Mo Complex Absorption Edge Information

\begin{tabular}{|c|c|c|}
\hline Compd & $\begin{array}{l}\text { Formal Mo } \\
\text { oxidn state }\end{array}$ & $\begin{array}{c}\text { Inflection point } \\
\text { energy, eV }\end{array}$ \\
\hline $\mathrm{MoS}_{2}$ & IV & 20010.4 \\
\hline $\mathrm{Mo}\left(\mathrm{S}_{2} \mathrm{CNEt}_{2}\right)\left(\mathrm{S}_{2} \mathrm{C}_{6} \mathrm{H}_{4}\right)_{2}$ & V & 20010.5 \\
\hline$\left(\mathrm{MoS}_{4}\right)^{2-}$ & VI & 20011.1 \\
\hline $\mathrm{MoCl}_{3}$ & III & 20010.7 \\
\hline $\mathrm{MoCl}_{4}$ & IV & 20012.7 \\
\hline $\mathrm{MoCl}_{5}$ & $\mathrm{~V}$ & 20014.3 \\
\hline $\mathrm{MoO}_{2}$ & IV & 20015.4 \\
\hline $\mathrm{MoO}(\mathrm{OH})_{3}$ & V & 20017.7 \\
\hline $\mathrm{MoO}_{3}$ & VI & 20018.9 \\
\hline
\end{tabular}

II) then reveals that an inflection point of $20011.5 \mathrm{eV}$ is a fairly low value, most characteristic of sulfur ligation. ${ }^{26}$ It has been observed that the presence of a single oxygen in $\mathrm{Mo}^{\mathrm{IV}} \mathrm{O}\left(\mathrm{S}_{2} \mathrm{CNEt}_{2}\right)_{2}$ yields an edge inflection point of 20012.1 $\mathrm{eV}^{25}$ and that increases in the number of oxygens for a given oxidation state shift the edge to even higher energies (the $\mathrm{Mo}^{\text {IV }} \mathrm{O}_{2}$ edge is at $20015.4 \mathrm{eV}$ ). Thus, from the edge data alone, it appears unlikely that $\mathrm{Cp}{ }^{\text {sr }}$ would have more than a single oxygen ligand. The lack of suitable Mo-N complex data precludes estimation of the possible number of nitrogens from the current edge data.

When sulfur ligation is predominant, the absorption edge position is relatively insensitive to changes in the Mo oxidation state. Although molybdenum chlorides and oxides show edge shifts of as much as $2 \mathrm{eV}$ per unit oxidation state change, molybdenum-sulfur compounds exhibit changes of $0.5 \mathrm{eV}$ or less per unit change. ${ }^{25}$ These small shifts are within the experimental error of the edge position measurements. Thus, although the $\mathrm{Cpl}^{\mathrm{sr}}$ edge is in a region indicative of sulfur ligation (and clearly too low for primarily oxygen ligation), little can be said about the formal Mo oxidation state from these data alone.

The shape of the $\mathrm{Cp}^{\mathrm{sr}}$ edge, a smooth rise with a single inflection point (see Figure 2), can be used to eliminate both a tetrahedral environment and doubly bound oxygen coordination. Mixing of $d, s$, and $p$ character in the orbitals produced 
by covalent bonding and/or tetrahedral symmetry makes hybrid orbitals accessible and gives intensity to extra bound state transitions. ${ }^{27}$ The enhancement of the $1 \mathrm{~s}-4 \mathrm{~d}$ transition has been clearly observed in molybdates and thiomolybdates. ${ }^{25}$ This particular transition generally produces an extra shoulder or peak in the Mo absorption edges, as in the $\left(\mathrm{MoS}_{4}\right)^{2-}$ edge of Figure 2. The absence of such a feature in the $\mathrm{Cp}^{\text {ls }}$ edge permits elimination of strictly tetrahedral geometry for Mo.

Similar enhancement of the $1 \mathrm{~s}-4 \mathrm{~d}$ transition occurs for molybdenum complexes with doubly bound oxygen. All molybdenum complexes with $\mathrm{Mo}=\mathrm{O}$ examined to date, whether $\mathrm{Mo}(\mathrm{IV}), \mathrm{Mo}(\mathrm{V})$, or $\mathrm{Mo}$ (VI), exhibit this characteristic bound state transition. ${ }^{25}$ The intensity of this transition varies directly with the number of $\mathrm{Mo}=\mathrm{O}$ bonds. Complexes with one or two $\mathrm{Mo}=\mathrm{O}$ bonds exhibit a low-energy shoulder on the absorption edge, while a distinct peak appears when three or four $\mathrm{Mo}=\mathrm{O}$ are present. The low-energy feature under discussion is clearly visible in the air-oxidized protein and model compound data of Figure 3. The Cplss edge exhibits no such feature, and doubly bound oxygen can, therefore, be excluded as a possible ligand.

The edges of the "fully reduced" and "dye-oxidized" states (Figure 1) are extremely similar to the $\mathrm{Cpl}$ sr edge. Since $\mathrm{Cp}{ }^{\text {fr }}$ and $\mathrm{Cp}{ }^{\text {do }}$ also exhibit smooth, low-energy, single inflection point edges, the arguments presented above for sulfur ligation and against tetrahedral geometry and doubly bound oxygen hold for these states as well. The positions of all three inflection points, although not identical, are within experimental error of being the same. ${ }^{28}$

Given the present (and following) evidence for sulfur ligation, it is conceivable that oxidation state changes of the molybdenum would not produce edge changes larger than experimental error, and it is thus not possible from these data to say whether or not the molybdenum is involved in the overall change of protein oxidation level. At least it can be said that there are no drastic differences in the Mo coordination sphere (as far as ligand or geometry changes are concerned) between these three states.

The state which did exhibit significant differences in both edge position and shape was the air-oxidized Clostridial MoFe protein. The $\mathrm{Cpl}{ }^{\text {ao }}$ edge has a distinct low-energy inflection point at $20004.9 \mathrm{eV}$, as well as a higher inflection point at $20016.6 \mathrm{eV}^{29}$ (see Figure 3). Both the shape and position of the $\mathrm{Cp} \mathrm{l}^{\text {ao }}$ edge are characteristic of $\mathrm{Mo}(\mathrm{V})$ or $\mathrm{Mo}(\mathrm{VI})$ coordinated by two or more oxygen ligands. From the intensity of the bound state transition shoulder it appears likely that the molybdenum is ligated by one or two doubly bound oxygens. The presence of other less tightly bound oxygens cannot be excluded because they would have little effect on the shape of the edge. However, three or four $\mathrm{Mo}=\mathrm{O}$ would produce a resolved low-energy peak. ${ }^{25}$ Although the air-oxidized spectrum provides no information about the physiologically active states of nitrogenase molybdenum, it is a useful reference spectrum for confirming that the other current $\mathrm{Cpl}$ spectra do not correspond to $\mathrm{O}_{2}$-inactivated material.

The EXAFS Region. The extended $x$-ray absorption fine structure $\chi(k)$ is defined as the modulation of the absorption coefficient $\mu$ on the high-energy side of the absorption edge:

$$
\chi(k)=\frac{\mu-\mu_{\mathrm{s}}}{\mu_{0}}
$$

In this expression $\mu_{0}$ is the absorption coefficient that would be observed for the absorber in the absence of neighboring scattering atoms, $\mu_{\mathrm{s}}$ is the smoothly varying part of the observed absorption, and $k$ is the photoelectron wave vector.

By making a number of approximations, one can arrive at a general expression for the EXAFS $\chi(k)$, in terms of calculatable physical quantities:

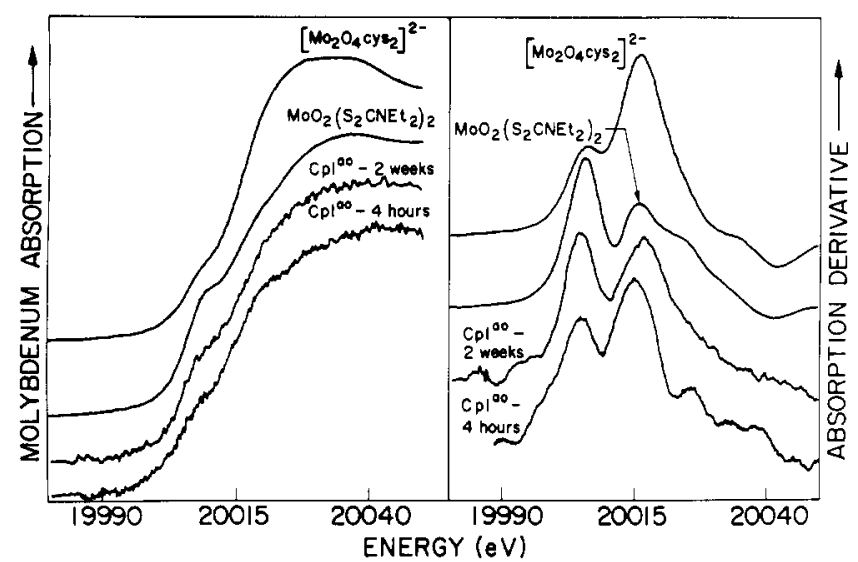

Figure 3. A comparison of $\mathrm{Cp}^{\mathrm{aO}}$ (after both $4 \mathrm{~h}$ and 2 weeks of air exposure) with the two molybdenum compounds containing both oxygen and sulfur ligands. The pairs of inflection points (from top to bottom) were 20006.2 and $20016.2,20005.6$ and $20016.2,20004.9$ and 20016.6 , and 20004.9 and $20014.9 \mathrm{eV}$. The Mo compound spectra are presented mainly to show the effects of one or two $\mathrm{Mo}=\mathrm{O}$ on the shape of the Mo absorption edge. The $1 \mathrm{~s}-4 \mathrm{~d}$ transition is now a clear shoulder on the edge, producing the low-energy inflection point in the absorption spectrum which appears as a separate peak in the derivative spectrum-a distinct difference from the edge of $\mathrm{Cpl}^{\mathrm{sr}}$.

$$
\begin{aligned}
\chi(k) \equiv \frac{\mu-\mu_{\mathrm{s}}}{\mu_{0}}=\frac{1}{k} \sum_{\mathrm{s}} N_{\mathrm{s}} & \frac{\left|f_{\mathrm{s}}(\pi, k)\right|}{R_{\mathrm{as}}^{2}} \\
& \times \sin \left(2 k R_{\mathrm{as}}+\alpha_{\mathrm{as}}(k)\right) e^{-\sigma_{\mathrm{as}}^{2} k^{2}}
\end{aligned}
$$

In this expression, $N_{\mathrm{s}}$ is the number of scatterers (s) at distance $R_{\mathrm{as}}$ from the absorber (a); $f_{\mathrm{s}}(\pi, k)$ is the scatterer's electron backscattering amplitude; $\alpha_{\mathrm{as}}$ is the total phase shift, and $\sigma_{\mathrm{as}}^{2}$ is the mean square deviation of $R_{\mathrm{as}}$. The derivation of this expression ${ }^{38}$ involves a number of approximations which break down at low values of $k$ (close to the absorption edge). Also, for scattering atoms beyond the first coordination sphere one must account for additional effects which diminish the photoelectron wave amplitude and/or change its phase as it propagates from the absorber.

For the purpose of understanding the EXAFS of nitrogenase, it is important to consider the physical quantities which affect the fine structure. First of all, the oscillatory part of the fine structure is related to the argument of the sine function in eq $2: 2 k R_{\text {as }}+\alpha_{\text {as }}(k)$. From this we see that the frequency of the EXAFS oscillations is proportional to the distance between the absorber and scatterer (in the present case Mo and the surrounding ligands). Furthermore, the phase shift $\alpha_{\text {as }}(k)$ (due to electron-atom backscattering and propagation out of and back through the Coulomb hole) will affect both the frequency and the absolute phase of the EXAFS. Finally, the EXAFS amplitude will be directly proportional to the number of scatterers $N_{\mathrm{s}}$, weighted by their electron-atom backscattering amplitudes $f_{\mathrm{s}}(\pi, k)$ and damped by both an inverse square distance dependence $\left(1 / R_{\mathrm{as}}^{2}\right)$ and a Debye-Waller-like exponential dependence on fluctuations of $R_{\mathrm{as}}: e^{-\sigma_{\mathrm{as}}^{2} k^{2}}$. The summation index of eq 2 is over all scattering atoms in the vicinity of the absorber; thus, the EXAFS of any absorber with a complicated coordination sphere will be a superposition of the individual components. The reader unfamiliar with EXAFS is urged to consult ref 21 and references cited therein for further details on the physics of EXAFS and current analysis methods.

The EXAFS of lyophilized $\mathrm{Cp}^{\mathrm{sr}}$ is presented in Figure 4. An important feature of the $k$ space EXAFS data is the presence of a beat pattern with maxima near 6 and $12.5 \AA^{-1}$ and a minimum near $9.5 \AA^{-1}$. This modulation of the EXAFS amplitude envelope indicates the presence of at least two fre- 
Table III. Fourier Transform Calculations ${ }^{c}$

\begin{tabular}{|c|c|c|c|c|c|c|c|}
\hline & \multicolumn{2}{|c|}{ Peak } & \multicolumn{5}{|c|}{ Postulated scatterer } \\
\hline & Position & Magnitude & $N$ & $\mathrm{O}$ & $\mathrm{S}$ & $\mathrm{Fe}$ & Mo \\
\hline \multicolumn{8}{|l|}{ A } \\
\hline & 1.43 & 0.055 & $\begin{array}{r}1.86 \\
(2.5)\end{array}$ & $\begin{array}{r}1.84 \\
(1.5)\end{array}$ & $\begin{array}{r}1.89 \\
(0.9)\end{array}$ & $\begin{array}{r}1.83 \\
(0.5)\end{array}$ & $\begin{array}{r}1.82 \\
(0.2)\end{array}$ \\
\hline & 1.86 & 0.137 & 2.29 & 2.27 & 2.32 & 2.26 & 2.25 \\
\hline & & & $(9.6)$ & $(5.7)$ & $(3.5)$ & $(2.0)$ & $(0.9)$ \\
\hline & 2.32 & 0.081 & 2.75 & 2.73 & 2.78 & $2.72^{a}$ & 2.71 \\
\hline \multicolumn{3}{|c|}{$(1.7)$} & (8.1) & $(4.9)$ & $(2.9)$ & $(1.7)$ & $(0.7)$ \\
\hline D & 1.31 & 0.035 & 1.78 & 1.75 & 1.80 & 1.75 & 1.70 \\
\hline & & & $(1.7)$ & $(1.0)$ & $(0.6)$ & $(0.4)$ & $(0.2)$ \\
\hline & 1.84 & 0.109 & 2.31 & 2.28 & 2.33 & 2.28 & 2.23 \\
\hline & & & $(9.0)$ & (5.4) & $(3.2)$ & $(1.9)$ & $(1.0)$ \\
\hline & 2.29 & 0.06 & 2.76 & 2.73 & 2.78 & $2.73^{b}$ & 2.68 \\
\hline & & & $(7.0)$ & $(4.5)$ & $(2.5)$ & $(1.5)$ & $(0.8)$ \\
\hline
\end{tabular}

${ }^{a}$ Using approximate $\alpha_{\mathrm{FT}}$ of $0.4 \AA$ and $M_{\mathrm{FT}}$ of $0.35 .{ }^{b}$ Using approximate $\alpha_{\mathrm{FT}}$ of $0.44 \AA$ and $M_{\mathrm{FT}}$ of $0.30 .^{c} \mathrm{~A}$, transform range $4-14 \AA^{-1}$; $B$, transform range $4-12 \AA^{-1}$. All distances are in $\AA$. The values in parentheses are the calculated numbers of atoms.

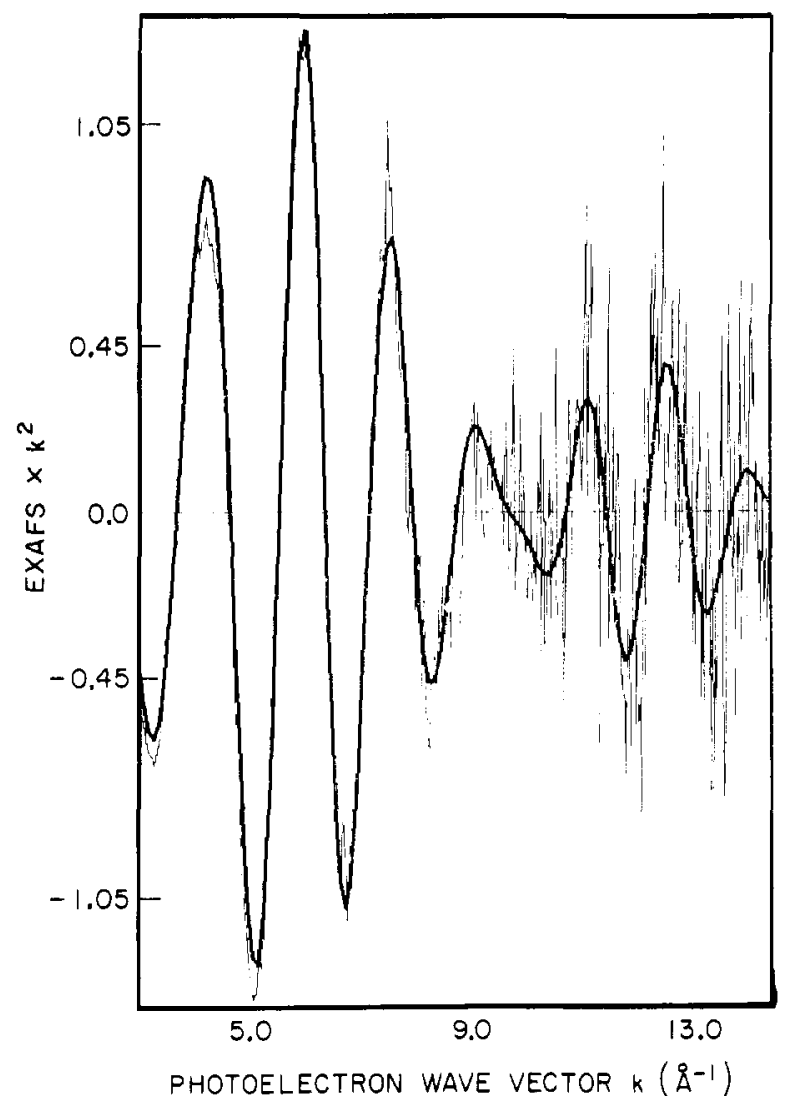

Figure 4. The original (light) and Fourier-filtered (dark) EXAFS of lyophilized Cplsr. The Fourier filtering involved transforming the $k$-space data (from 3 to $14.5 \AA^{-1}$ ) to $R$ space, then back-transforming to $k$ space only those components between 1 and $3 \AA$. Note the beat pattern in the EXAFS amplitude envelope, indicating the presence of at least two different absorber-scatterer distances.

quency components - that is, at least two different absorberscatterer distances. The frequency of this beat pattern, given by $\nu_{\text {beat }} \simeq 2 \pi / 6.5 \AA^{-1} \simeq 1 \AA$, indicates that the two major components of the EXAFS have a frequency difference of about $1 \AA$. Since the frequency of the oscillatory part of each component (neglecting the phase shift) depends upon twice the absorber-scatterer distance, the difference in distances would be about $0.5 \AA$ if the phase shift $\alpha_{\text {as }}(k)$ had approximately equal slope and curvature.

The above discussion indicates that even a relatively simple examination of the Cpls ${ }^{\text {sr }}$ EXAFS shows that at least two dif- ferent kinds of neighboring atoms have to be accounted for in an analysis of the Mo environment. In order to extract the maximum amount of information available from the fine structure, the phase, frequency, and magnitude of the EXAFS components have been analyzed to determine the types of atoms close to $\mathrm{Mo}$, their distances to $\mathrm{Mo}$, and the number in each coordination shell.

Fourier Transform Analysis. Use of the Fourier transform to analyze EXAFS was introduced by Sayers, Lytle, and Stern. ${ }^{30}$ They have shown that the major peaks in the transform correspond to the important absorber-scatterer distances, but shifted to lower $R$ by a few tenths of an ångstrom. Fourier transformation of $k$-space EXAFS data is a useful means of observing the major frequency components. The transform peak height is related to the magnitude of a particular frequency component, while the peak position is related to $1 / 2$ the average frequency of that component. ${ }^{31}$ Once the effective phase shift $\alpha_{F T}$ (the difference between the observed peak position and true distance) and the effective per atom magnitude $M_{\mathrm{FT}}$ (the observed peak height $\times R^{2} / N$ ) have been obtained from analysis of model compounds, the transform peak positions and peak heights observed for an unknown compound can be used to predict scatterer distances and numbers. The application of this procedure to a variety of molybdenum structures has been discussed in detail in ref 21 .

The Fourier transform spectrum of lyophilized $\mathrm{Cpl}^{\text {sr }}$ (Figure 5) in the range of $4-14 \AA^{-1}$ shows a major peak at $1.86 \AA$, a peak of $60 \%$ relative intensity at $2.32 \AA$, and a minor peak of $40 \%$ relative intensity at $1.43 \AA$ (the low $R$ peak at $1.43 \AA$ strongly resembles the shoulders caused by phase shift nonlinearity, as typified in Figure 6 of ref 21). For the preliminary analysis it has been presumed that each of these features corresponds to a real Mo-scatterer distance, and a further assumption is that the biochemically reasonable assignments for the peak will be either N, O, S, Fe, or Mo. Using previously calculated effective phase shifts and per atom magnitudes, a set (Table III) of possible scatterer distances and numbers can be constructed. One can now compare these calculated values with typical bond lengths (Table IV) in order to decide which assignments are chemically reasonable.

The Fourier transform calculations reveal that the primary peak would correspond to about nine or ten nitrogens at 2.29 $\AA$, five or six oxygens at $2.27 \AA$, or three or four sulfurs at 2.32 $\AA$. Comparison of these values with the typical Mo-X bond lengths of Table IV shows that the most chemically reasonable assignment is that the primary EXAFS component is due to about three or four sulfurs. The higher $R$ peak could be either 
Table IV. Typical Mo-X Bond Lengths ${ }^{r}$

\begin{tabular}{|c|c|c|c|}
\hline Bond type & $\begin{array}{c}\text { Bond } \\
\text { length, } \AA\end{array}$ & Structure & Ref \\
\hline \multirow[t]{2}{*}{ Mo- $N_{\text {imid }}$} & 2.21 & $\mathrm{Mo}_{2}^{\mathrm{V}} \mathrm{O}_{2} \mathrm{O}_{2} \mathrm{His}_{2}$ & $a$ \\
\hline & 2.22 & $\mathrm{Mo}_{2} \mathrm{~S}_{2} \mathrm{O}_{2} \mathrm{His}_{2}$ & $b$ \\
\hline \multirow[t]{2}{*}{ Mo- $\mathrm{N}_{\text {amino }}$} & 2.23 & {$\left[\mathrm{Mo}^{v} \mathrm{O}_{2} \mathrm{O}_{2} \mathrm{Cys}_{2}\right]^{2-}$} & $c$ \\
\hline & 2.24 & $\mathrm{Mo}_{2} \mathrm{O}_{2} \mathrm{O}_{2} \mathrm{His}_{2}$ & $a$ \\
\hline \multirow[t]{5}{*}{$\mathrm{Mo}=\mathrm{O}$} & 1.66 & $\mathrm{Mo}^{\mathrm{IV}} \mathrm{O}\left(\mathrm{S}_{2} \mathrm{CNPr}_{2}\right)_{2}$ & $d$ \\
\hline & 1.695 & $\mathrm{Mo}^{\mathrm{VI} \mathrm{O}_{2}}\left(\mathrm{~S}_{2} \mathrm{CNPr}_{2}\right)_{2}$ & $d$ \\
\hline & 1.71 & $\mathrm{Mo}_{2}^{\vee} \mathrm{O}_{2} \mathrm{O}_{2} \mathrm{His}_{2}$ & $a$ \\
\hline & 1.74 & $\mathrm{Mo}^{\mathrm{VI}} \mathrm{O}_{3}$ dien & $e$ \\
\hline & 1.76 & $\left(\mathrm{MoVI}_{4}\right)^{2-}$ & $f$ \\
\hline \multirow[t]{4}{*}{$\mathrm{Mo}-\mathrm{O}_{b}$} & 1.85 & $\mathrm{Mo}_{2}^{\mathrm{y}} \mathrm{O}_{3}\left(\mathrm{~S}_{2} \mathrm{COEt}\right)_{4}$ & $g$ \\
\hline & 1.92 & $\mathrm{Mo}_{2} \mathrm{O}_{2} \mathrm{O}_{2} \mathrm{His}_{2}$ & $a$ \\
\hline & 1.93 & {$\left[\mathrm{Mo}_{2} \mathrm{O}_{2} \mathrm{O}_{2} \mathrm{Cys}_{2}\right]^{2-}$} & $c$ \\
\hline & 1.94 & $\mathrm{Mo}_{2} \mathrm{O}_{2} \mathrm{O}_{2}\left(\mathrm{~S}_{2} \mathrm{CNEt}_{2}\right)_{2}$ & $h$ \\
\hline \multirow[t]{5}{*}{ Mo-O } & 2.11 & {$\left[\mathrm{Mo}_{2} \mathrm{~S}_{2} \mathrm{O}_{2}(\text { edta })\right]^{2-}$} & $i$ \\
\hline & 2.195 & {$\left[\mathrm{MoVI}_{3}(\text { edta }) \mathrm{Mo}^{\mathrm{VI}} \mathrm{O}_{3}\right]^{4-}$} & $j$ \\
\hline & 2.21 & $\mathrm{Mo}_{2}^{\mathrm{y}} \mathrm{O}_{2} \mathrm{O}_{2} \mathrm{His}_{2}$ & $a$ \\
\hline & 2.24 & $\mathrm{Mo}_{2} \mathrm{~S}_{2} \mathrm{O}_{2} \mathrm{His}_{2}$ & $b$ \\
\hline & 2.30 & {$\left[\mathrm{Mo}_{2} \mathrm{O}_{2} \mathrm{O}_{2} \mathrm{Cys}_{2}\right]^{2-}$} & $c$ \\
\hline \multirow[t]{2}{*}{$\mathrm{Mo}=\mathrm{S}$} & 1.94 & $\mathrm{Mo}_{2}^{\mathrm{v}} \mathrm{S}_{2} \mathrm{~S}_{2}\left[\mathrm{~S}_{2} \mathrm{CN}\left(\eta-\mathrm{C}_{4} \mathrm{H}_{9}\right)_{2}\right]_{2}$ & $k$ \\
\hline & 2.18 & $\left(\mathrm{Mo}^{\mathrm{VI}} \mathrm{S}_{4}\right)^{2-}$ & $l$ \\
\hline \multirow[t]{6}{*}{ Mo-S } & 2.29 & {$\left[\mathrm{Mo}_{2} \mathrm{~V}_{2} \mathrm{O}_{2}(\text { edta })\right]^{2-}$} & $i$ \\
\hline & 2.31 & $\mathrm{Mo}_{2} \mathrm{~S}_{2} \mathrm{O}_{2}(\mathrm{Cys}-\mathrm{Me})_{2}$ & $m$ \\
\hline & 2.33 & $\mathrm{Mo}^{\mathrm{v}} \mathrm{S}_{2} \mathrm{O}_{2} \mathrm{His}_{2}$ & $b$ \\
\hline & 2.33 & $\left(\eta^{5}-\mathrm{C}_{5} \mathrm{H}_{5}\right)_{3} \mathrm{Mo}_{3} \mathrm{FeS}_{4} \mathrm{Br}$ & $p$ \\
\hline & 2.34 & $\left(\eta^{5}-\mathrm{C}_{5} \mathrm{H}_{5}\right)_{3} \mathrm{Mo}_{3} \mathrm{FeS}_{4} \mathrm{Cl}$ & $p$ \\
\hline & 2.41 & $\mathrm{Mo}^{\mathrm{IV}} \mathrm{S}_{2}$ & $n$ \\
\hline \multirow[t]{10}{*}{ Mo-S cys $_{\text {s }}$} & 2.38 & $\mathrm{Mo}_{2}^{\mathrm{V}} \mathrm{S}_{2} \mathrm{O}_{2}(\text { Cys-Me })_{2}$ & $m$ \\
\hline & 2.385 & $\mathrm{Mo}_{2} \mathrm{O}_{2} \mathrm{O}_{2}$ (Cys-Et $)_{2}$ & $o$ \\
\hline & 2.49 & {$\left[\mathrm{Mo}_{2} \mathrm{O}_{2} \mathrm{O}_{2} \mathrm{Cys}_{2}\right]^{2-}$} & $c$ \\
\hline & 2.76 & $\left(\eta^{5}-\mathrm{C}_{5} \mathrm{H}_{5}\right)_{3} \mathrm{Mo}_{3} \mathrm{FeS}_{4} \mathrm{Br}$ & $p$ \\
\hline & 2.78 & $\left(\eta^{3}-\mathrm{C}_{5} \mathrm{H}_{5}\right)_{3} \mathrm{Mo}_{3} \mathrm{FeS}_{4} \mathrm{Cl}$ & $p$ \\
\hline & 2.55 & $\mathrm{Mo}_{2}^{\mathrm{Y}} \mathrm{O}_{2} \mathrm{O}_{2} \mathrm{His}_{2}$ & $a$ \\
\hline & 2.57 & {$\left[\mathrm{Mo}_{2} \mathrm{O}_{2} \mathrm{O}_{2} \mathrm{Cys}_{2}\right]^{2-}$} & $c$ \\
\hline & 2.67 & $\mathrm{Mo}_{2}^{\mathrm{V}} \mathrm{O}_{3} \mathrm{~S}\left(\mathrm{~S}_{2} \mathrm{CNPr}\right)_{2}$ & $q$ \\
\hline & 2.80 & $\mathrm{Mo}^{\mathrm{v}} \mathrm{S}_{2} \mathrm{O}_{2}$ (Cys-Me $)_{2}$ & $m$ \\
\hline & 2.85 & $\mathrm{Mo}_{2} \mathrm{~S}_{2} \mathrm{O}_{2} \mathrm{His}_{2}$ & $b$ \\
\hline
\end{tabular}

${ }^{a}$ L. T. J. Delbaere and C. K. Prout, Chem. Commun., 162 (1971). ${ }^{b}$ B. Spivack and Z. Dori, J. Chem. Soc., Dalton Trans. 1077 (1975). ' J. R. Knox and C. K. Prout, Acta Crystallogr., Sect. B, 25, 1857 (1969). ${ }^{d}$ L. Ricard, J. Estienne, P. Karagiannidis, P. Toledano, J. Fisher, A. Mitschler, and R. Weiss, J. Coord. Chem., 3, 277 (1974). ${ }^{e}$ F. A. Cotton and R. C. Elder, Inorg. Chem., 3, 397 (1964). ${ }^{f}$ B. M. Gatehouse and P. Leverett, J. Chem. Soc. A, 849 (1969). 8 A. B. Blake, F. A. Cotton, and J. S. Wood, J. Am. Chem. Soc., 86, 3024 (1964). ${ }^{h}$ L. Ricard, C. Martin, R. West, and R. Weiss, Inorg. Chem., 14, 2300 (1975). 'B. Spivack and Z. Dori, J. Chem. Soc., Dalton Trans., 1173 (1973). ${ }^{j}$ J. J. Park, M. D. Glick, and J. L. Hoard, J. Am. Chem. Soc., 91, 301 (1969). ${ }^{k}$ B. Spivack, Z. Dori, and E. I. Stiefel, Inorg. Nucl. Chem. Lett., 11, 501 (1975). ${ }^{l}$ W. P. Binnie, M. J. Redman, and W. J. Mallo, Inorg. Chem., 9, 1449 (1970), ${ }^{m}$ M. G. B. Drew and A. Kay, J. Chem. Soc. A, 1851 (1971). ${ }^{n}$ R. G. Dickinson and L. Pauling, J. Am. Chem. Soc., 45, 1466 (1923). ${ }^{\circ}$ M. G. B. Drew and A. Kay, J. Chem. Soc. A, 1846 (1971), ${ }^{p}$ L. Dahl, private communication. ${ }^{a}$ J. Dirand-Colin, L. Ricard, and R. Weiss, Inorg. Chim. Acta, 18, L21 (1976). ${ }^{r}$ Abbreviations: $\mathrm{N}_{\text {imid, histidine imidazole }}$ nitrogen; $X_{b}$, bridging $X ; O_{c a r b}$, carboxylate oxygen; $S_{c y s}$, cysteine sulfur.

sulfido-bridged iron or molybdenum, while the lower $R$ peak, if real, must be nitrogen or oxygen. Using the transform distances and scatterer numbers for starting values, a curve-fitting analysis of the EXAFS has been carried out. For complicated coordination spheres with overlapping EXAFS Fourier

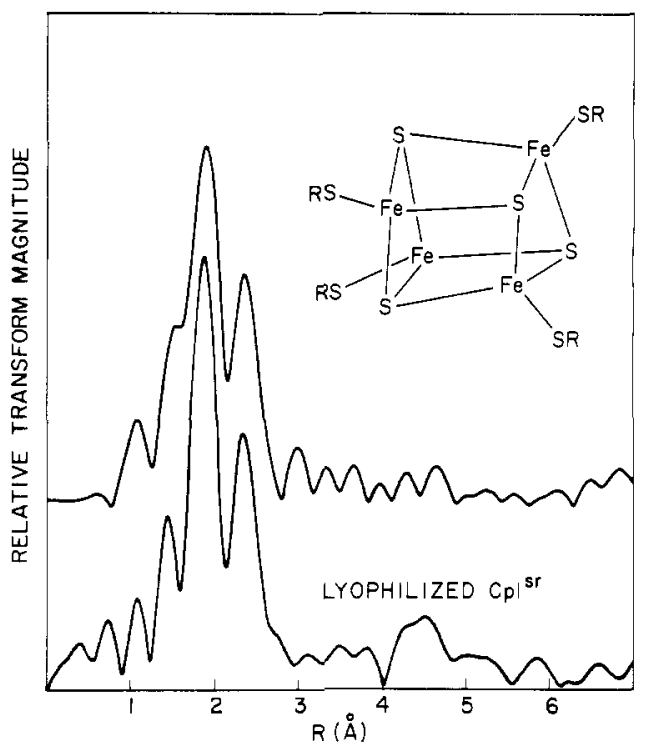

Figure 5. The Fourier transform (moduli only) of lyophilized $\mathrm{Cp}{ }^{\mathrm{sr}}$ and $\left[\mathrm{Fe}_{4} \mathrm{~S}_{4}\left(\mathrm{SCH}_{2} \mathrm{Ph}\right)_{4}\right]^{2-}$. If a Mo atom were substituted for a single Fe atom in the tetramer, while keeping all distances the same, the magnitude of the resulting Mo EXAFS Fourier transform would look very similar to the original Fe transform, but phase shifted an extra $0.09 \AA$ to lower $R$.

transform peaks, curve-fitting procedures yield more precise distances and better scatterer numbers, as well as elemental identification of the scatters involved. ${ }^{21}$

Curve-Fitting Analysis. In a previous paper $^{21}$ a procedure for curve-fitting the extended fine structure by means of empirical phase shift and amplitude functions has been described in detail. The total EXAFS $\chi(k)$ was described as the sum of individual absorber-scatterer interactions, thus:

$$
\chi(k)=\sum_{\mathrm{s}} \chi_{\mathrm{as}}(k)
$$

where the sum over scatterers can often neglect atoms beyond $3 \AA$ from the absorber. ${ }^{32}$ The individual interactions were parametrized in terms of a pairwise amplitude function:

$$
A_{\text {as }}(k)=c_{0} e^{-c_{1} k^{2} / k^{c_{2}}}
$$

and a pairwise phase shift:

$$
\alpha_{\mathrm{as}}(k)=a_{0}+a_{1} k+a_{2} k^{2}
$$

The best values for $c_{0}, c_{1}, c_{2}, a_{0}, a_{1}$, and $a_{2}$ were determined by curve-fitting the EXAFS of appropriate model compounds, and different values for Mo-C, Mo-N, Mo-O, Mo-S, and $\mathrm{Mo}-\mathrm{Mo}$ interactions were obtained. Since appropriate $\mathrm{Mo}-\mathrm{Fe}$ models are not available, Mo-Fe parameters were obtained through a combination of empirical and theoretical results. 33

The total EXAFS of an unknown structure is fitted with a sum of damped sine waves whose amplitude envelopes and phase shifts are predetermined by the above parameters:

$\chi(k)=\sum_{\mathrm{s}} \frac{c_{0 \mathrm{~s}} e^{-c_{1 \mathrm{~s}} k^{2}}}{k^{c_{2 \mathrm{~s}}}} \sin \left(a_{0 \mathrm{~s}}+a_{1 \mathrm{~s}} k+2 R_{\mathrm{as}} k+a_{2 \mathrm{~s}} k^{2}\right)$

In the fitting procedure, the parameters $c_{1}, c_{2}, a_{0}, a_{1}$, and $a_{2}$ are held to different fixed values depending on the elemental assignment of the scatterer. The values of $c_{0}$ and $R_{\mathrm{as}}$ are varied by the optimization program to give the best fit to the data. If the elemental assignments for the scatterers are correct, then $R_{\text {as }}$ will be the distance from the absorber (in this case $\mathrm{Mo}$ ) to 


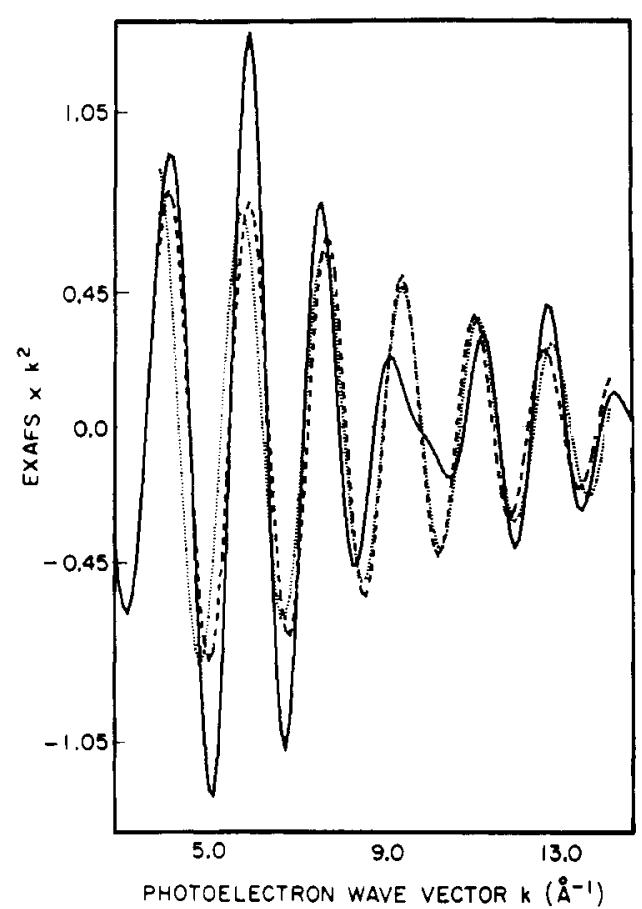

Figure 6. Fourier-filtered $\mathrm{Cp} \mathrm{p}^{\mathrm{sr}}$ data $(-)$ fit with either a single Mo-S wave $(-\ldots .$.$) or a single Mo-O wave \left(\cdots \cdots s^{-}\right)$. The phase shifts used were empirical values from ref 21 . The Mo-O wave is clearly out of phase with most of the data; it adjusts as well as possible by leading the Cpl ${ }^{\text {sr }} \mathrm{EXAFS}$ at low $k$ and trailing it at high $k$. The single-shell fit using Mo-S parameters yielded values of 3.4 sulfurs at $2.36 \AA$, while the fit using Mo-O parameters predicted 4.7 oxygens at $2.21 \AA$. Fit range: $4-14 \AA^{-1}, k^{6}$ weighting.

the scatterer, while the value of $c_{0}$ can be used to obtain the approximate number of scatterers of that type.

The first fits on the filtered $\mathrm{Cp}^{\text {ls }}$ EXAFS were designed to determine the source of the primary component of the fine structure. The optimization program was run with a single sine wave, using the phase shift and amplitude parameters for either Mo-O or Mo-S, and varying both the number of atoms (via $c_{0}$ ) and their distance to molybdenum (via $R_{\text {as }}$ ). The resultant fits (Figure 6) show that Mo-S parameters describe the phase of the EXAFS before the beat region substantially better than do Mo-O parameters. Since the strongest EXAFS component dominates the phase of the fine structure in this region, these fits support the previous conclusions based on edge data about primarily sulfur ligation to the molybdenum.

A successful curve-fitting analysis should produce a much better fit than those of Figure 6, and it was, therefore, important to know how many additional components were required to adequately reproduce the EXAFS. From the Fourier transform data (Table III), it appeared that the next wave to be added should correspond to a single molybdenum or several sulfurs or irons at a distance of about $2.7 \AA$. Two-shell fits on the $\mathrm{Cp} \mathrm{l}^{\mathrm{sr}}$ EXAFS were thus attempted using either (Mo-S and Mo-Mo), (Mo-S and Mo-S), or (Mo-S and Mo-Fe) parameters. The best fits (Figure 7 and Table $\mathrm{V}$ ) indicate that the second component is most likely a Mo-Fe interaction. This conclusion is based on two observations. First, the best (Mo-S $+\mathrm{Mo}-\mathrm{Fe}$ ) fit yielded a lower error function than any (Mo-S + Mo-Mo) or (Mo-S + Mo-S) fit. Second, the best fit using Mo-Mo parameters gave a negative Mo amplitude, indicating that the Mo-Mo phase shift is substantially out of phase with the high $R$ component. Although these results do not yet prove the presence of Mo-Fe interactions, they make it very unlikely that the Mo in nitrogenase is present as a bridged Mo-Mo dimer.

Despite the improved fits obtained using two different waves,

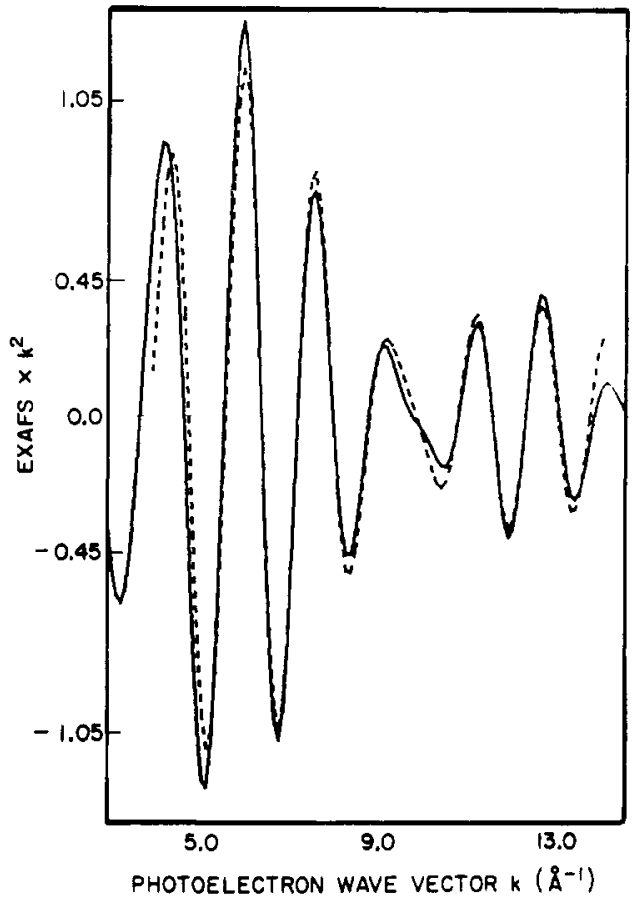

Figure 7. Fourier-filtered $\left.\mathrm{Cp}\right|^{\text {sr }}$ data $(-)$ fit with a $\mathrm{Mo}-\mathrm{S}$ wave and a Mo-Fe wave (-...). Fit range: $4-14 \AA^{-1}, k^{6}$ weighting.

Table V. Two-Wave Curve-Fitting Results ${ }^{a}$

\begin{tabular}{cccc}
\hline $\begin{array}{c}\text { Postulated } \\
\text { scattering } \\
\text { elements }\end{array}$ & $\begin{array}{c}\text { Calculated } \\
\text { scatterer } \\
\text { distances, } \AA\end{array}$ & $\begin{array}{c}\text { Calculated } \\
\text { scatterer } \\
\text { numbers }\end{array}$ & $\begin{array}{c}\text { Minimization } \\
\text { function } \\
\text { value }\end{array}$ \\
\hline S & 2.359 & 3.3 & 1.030 \\
+ & 2.847 & 2.6 & \\
S & 2.361 & 3.4 & $1.434^{b}$ \\
S & 2.861 & 0.5 & \\
+ & 2.366 & 4.4 & \\
Mo & 2.552 & -0.6 & $0.893^{b}$ \\
S & 2.365 & 3.6 & \\
+ & & & 0.843 \\
Mo & 2.705 & -0.7 & \\
S & 2.360 & 3.3 & \\
+ & & & 0.753 \\
Mo & 2.719 & 1.6 & \\
S & & & \\
+ & Fe & &
\end{tabular}

${ }^{a}$ Fitting range $4-14 \AA^{-1}, k^{6}$ weighting, ${ }^{b}$ Local minimum.

it was only with three components that the EXAFS could be adequately reproduced. Although the Fourier transform might be interpreted as requiring a low-frequency oxygen or nitrogen component, the greatest improvement to the fit came from adding another slightly longer Mo-S wave. The best three-shell fit on the range of $4-14 \AA^{-1}$ is presented in Figure 8 , while the calculated scatterer numbers and distances for this and the corresponding 4-12 $\AA^{-1}$ fit are presented in Table VI. The quality of this fit is of the same order as the fits obtained on model compounds of known structure, and there appears to be no justification for addition of new waves. Note that the region of greatest discrepancy between calculated and observed (filtered) EXAFS is the beat region from 9 to $11 \AA^{-1}$, as seen in Figure 4 . The precise shape of this beat region is the greatest ambiguity in the original spectra, and better data are required to determine whether the difference between calculated and observed EXAFS is significant. 
Table VI. Three-Wave Curve-Fitting Results

\begin{tabular}{|c|c|c|c|c|c|c|c|}
\hline \multirow{2}{*}{$\begin{array}{c}\text { Fitting } \\
\text { range, } \AA^{-1}\end{array}$} & \multirow{2}{*}{$\begin{array}{c}\text { Minimization } \\
\text { function } \\
\text { value } \\
\end{array}$} & \multicolumn{2}{|c|}{$\mathrm{S}_{1}$} & \multicolumn{2}{|c|}{$\mathrm{S}_{2}$} & \multicolumn{2}{|c|}{$\begin{aligned} \mathrm{Fe} \\
\end{aligned}$} \\
\hline & & Mo-S, $\AA$ & No. & Mo-S, $\AA$ & No. & $\mathrm{Mo}-\mathrm{Fe}, \AA$ & No. \\
\hline $4-12$ & 0.434 & 2.352 & 3.8 & 2.495 & 1.1 & 2.721 & 1.4 \\
\hline $4-14$ & 0.501 & 2.353 & 3.8 & 2.494 & 1.1 & 2.722 & 1.4 \\
\hline
\end{tabular}

\section{Discussion}

Since both $\mathrm{x}$-ray absorption edges and EXAFS are new and unfamiliar tools for the study of metalloproteins, it is useful at this point to summarize the conclusions about the $\mathrm{Cpl} \mathrm{mo-}$ lybdenum site, the methods and logic which led to these conclusions, and, finally, the relative stringency of the different findings. The various conclusions will be discussed separately and in order of decreasing certainty. At the end of this discussion the current results will be used to propose a pair of structures compatible with all the data.

The most clear-cut finding is that the Mo in nitrogenase is surrounded primarily by sulfur ligands. The absorption edge is in a low-energy region characteristic of all-sulfur ligation. The primary peak in the Fourier transform can be readily accounted for postulating three or four Mo-S distances of about $2.32 \AA$, while the alternative explanation of five or six Mo-O distances of $2.27 \AA$ appears much less chemically reasonable. ${ }^{36}$ The single wave fits showed that the absolute phase of the low $k$ fine structure is in very good agreement with empirical Mo-S phase shifts, and significantly different from Mo-O values. Finally, the successful three-wave fit of the EXAFS using two Mo-S waves and a Mo-Fe wave makes the conclusion about sulfur ligation virtually certain.

A second conclusion of nearly equal certainty is that no $\mathrm{Mo}=\mathrm{O}$ bonds exist in the fully reduced, semireduced, or dye-oxidized states of nitrogenase, and that air oxidation of the MoFe protein produces one or two such bonds (and possibly some Mo-O bonds). The evidence for this is the lack of a low-energy " $1 \mathrm{~s}-4 \mathrm{~d}$ " shoulder in the absorption edge of the first three states, and the appearance of such a feature upon air oxidation of $\mathrm{Cpl}$. The $\mathrm{Cp} \mathrm{l}^{\mathrm{fr}}, \mathrm{Cpl}^{\mathrm{sr}}$, and $\mathrm{Cp}^{\text {do }}$ edges all show a single inflection point, while $\mathrm{Cp}^{\text {ao }}$ shows two inflection points at positions characteristic of $\mathrm{Mo}(\mathrm{V})$ or $\mathrm{Mo}(\mathrm{VI})$ with doubly bound oxygen. There has been speculation ${ }^{37}$ that one of the roles of ATP in nitrogenase action might be in the removal of such oxygen, but the current edge data indicate that only the irreversibly oxidized $\mathrm{Cpl}^{20}$ contains $\mathrm{Mo}=\mathrm{O}$. Furthermore, the extreme similarity of the first three edges indicates that while the Mo oxidation state may or may not change between these different states, no major changes of the Mo coordination sphere occur.

Examination of the EXAFS, both directly in $k$ space or Fourier transformed in $R$ space, yielded the third result, the existence of a second set of scatterers about 0.4 or $0.5 \AA$ further from the Mo than the primary sulfur ligands. The existence of this second EXAFS component is revealed by the beat pattern in the EXAFS (between 9 and $11 \AA^{-1}$ ) as well as by the Fourier transform peak at $2.32 \AA$ (unshifted). A two-shell fitting analysis indicated that the phase of the second component is significantly different from the empirical Mo-Mo phase shift, and reasonably in phase with a calculated $\mathrm{Mo}-\mathrm{Fe}$ phase shift. Therefore, this second component is probably not due to $\mathrm{Mo}$, while the same analysis makes a Mo-Fe assignment very reasonable.

Unfortunately, Mo-Fe compounds with isolatable Mo-Fe EXAFS do not exist and, therefore, the empirical methods of ref 21 for the extraction of pairwise phase shift and amplitude functions could not be applied. The Mo-Fe amplitudes and phase shifts were calculated by a straightforward method, ${ }^{33}$ but unlike the other parametrized functions, they have not been

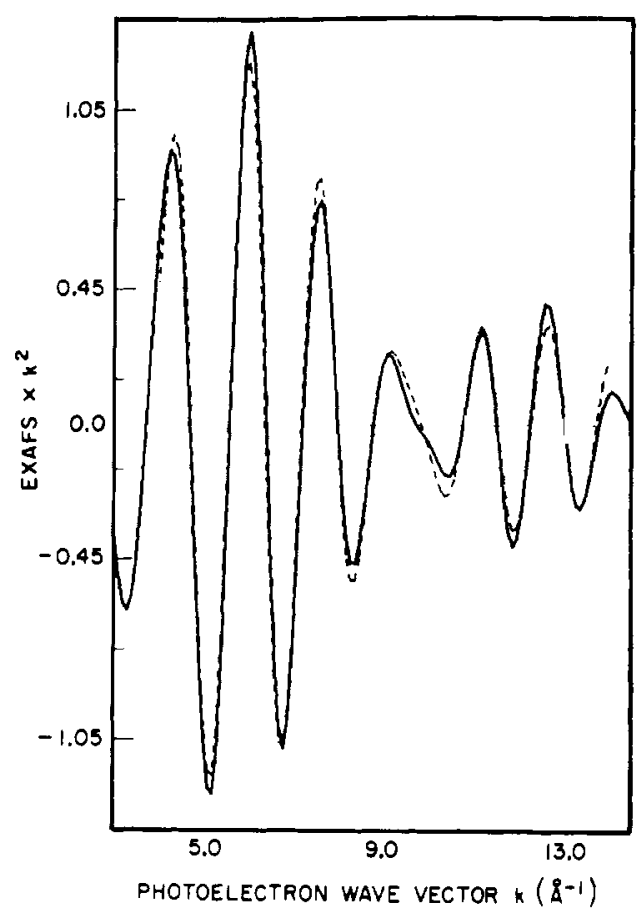

Figure 8. Fourier-filtered $\mathrm{Cp}^{\mathrm{sr}}$ data (-) fit with two different Mo-S waves and a Mo-Fe wave (- . - - ). Fit range: $4-14 \AA^{-1}, k^{6}$ weighting.

tested on known structures. The assignment of the second EXAFS component as a Mo-Fe interaction, although reasonable, is therefore not as unambiguous as the first two conclusions.

The final conclusions, stemming from the three-shell fit of Figure 8 and summarized in Table VI, are that Mo in lyophilized $\mathrm{Cpl}^{\mathrm{sr}}$ is surrounded by three or four sulfurs at $2.35 \pm 0.03$ $\AA$, one or two sulfurs at $2.49 \pm 0.03 \AA$, and two or three irons at $2.72 \pm 0.05 \AA$. The estimated accuracy is based on previous results ${ }^{21}$ rather than on statistical errors, since it is systematic errors which are the greatest source of uncertainty in EXAFS structure determination.

Experience with multishell fits on model compounds of known structure showed that distances were always calculated to better than $0.03 \AA$ when the correct scattering atoms were postulated. Furthermore, the calculated scatterer numbers were generally correct to within an atom. Thus the calculated values of $3.5 \mathrm{~S}$ at $2.35 \AA$ should be interpreted as three or four sulfurs with an average distance inside the range of 2.32-2.38 $\AA$ from the molybdenum. Since this component dominates the EXAFS, these values are the firmest numbers to be extracted from the fits.

Assuming that the longer distance secondary component to the EXAFS arises from a Mo-Fe interaction, the three-wave fit calculates $1.4 \mathrm{Fe}$ atoms at $2.72 \AA$. Since the $\mathrm{Fe}$ is most likely bridged through $\mathrm{S}$ to the Mo, this calculated number of irons should be considered a lower limit on the true value, based on the following considerations. First, atoms beyond the primary coordination sphere (not directly bound to the absorber) have greater thermal motion relative to the absorber than do ligated atoms, and increased thermal motion causes a reduction in the 
EXAFS amplitude. For example, the sulfido-bridged $\mathrm{Fe}-\mathrm{Fe}$ distance in the $2 \mathrm{Fe}-2 \mathrm{~S}$ cluster, $\left[\mathrm{Fe}_{2} \mathrm{~S}_{2}\left(\mathrm{~S}_{2}-0-\mathrm{xyl}\right)_{2}\right]^{2-}$, is essentially unobservable in the EXAFS of this compound, ${ }^{25}$ while the $\mathrm{Fe}-\mathrm{Fe}$ distance is quite distinct in the EXAFS of the more rigid $4 \mathrm{Fe}-4 \mathrm{~S}$ cluster $\left[\mathrm{Fe}_{4} \mathrm{~S}_{4}\left(\mathrm{SCH}_{2} \mathrm{C}_{6} \mathrm{H}_{5}\right)_{4}\right]^{-2}$ (see Figure 5). Since the amplitude calculations were based on a model with tightly bound ligands [i.e., $\mathrm{Mo}\left(\mathrm{S}_{2} \mathrm{C}_{6} \mathrm{H}_{4}\right)_{3}$ ], they will underestimate the number of more distant scatterers required to produce a given effect on the fine structure.

A second effect which reduces the EXAFS contribution of more distant shells is depletion of the outgoing photoelectron wave by intervening scatterers. Thus, the presence of sulfur atoms between the molybdenum (absorber) and iron (scatterer) might cause an additional reduction in the $\mathrm{Mo}-\mathrm{Fe}$ EXAFS. Although it is difficult to quantitate thermal motion and depletion effects, one should note that for sulfido-bridged Mo dimers, the strength of the Mo-Mo component is about $50 \%$ of that expected by comparison with oxo-bridged dimers. ${ }^{21}$ Thus, the calculated value of $1.4 \mathrm{Fe}$ atoms could in reality easily represent a contribution from two or three irons. Finally, the calculated Mo-Fe distance $(2.72 \pm 0.05 \AA)$ has a greater uncertainty than the Mo-S distances owing to possible inaccuracy in the calculated $\mathrm{Mo}-\mathrm{Fe}$ phase shift.

The third component of the three-wave fit may correspond to one or two sulfurs at an average distance of $2.49 \pm 0.03 \AA$. This component was necessary to produce an acceptable fit, but it is conceivable that better Mo-Fe phase shift and amplitude functions would make a third component unnecessary. On the other hand, a fourth wave corresponding to a single Mo-N distance would not be detectable. Although the calculated numbers are chemically reasonable, the amplitude of this component is only $25 \%$ that of the primary Mo-S wave, and these values are therefore subject to greater uncertainty.

Confronted with these three pairs of scatterer numbers and distances, and the general information about an all (or almost all) sulfur, non- $\mathrm{Mo}=\mathrm{O}$ environment, a model for the Mo site of nitrogenase can be formulated. It is useful to begin by comparing the calculated distances with bond lengths of known structures (Table IV). The calculated Mo-S distance of 2.35 $\AA$ is shorter than known Mo-S $\mathrm{S}_{\text {cys }}$ bond lengths, and slightly longer than known Mo- $\mathrm{S}_{\mathrm{b}}$ (bridging) bond lengths. An assignment as $\mathrm{Mo}(\mathrm{IV})-\mathrm{S}_{\mathrm{b}}$ or $\mathrm{Mo}$ (III) $-\mathrm{S}_{\mathrm{b}}$ is reasonable in view of the longer $\mathrm{Mo}-\mathrm{S}_{\mathrm{b}}$ bond lengths for lower oxidation states. The second Mo-S distance $(2.49 \AA)$ is in a region typical of $\mathrm{Mo}-\mathrm{S}_{\mathrm{cys}}$ bond lengths, although methionine or even persulfide $\mathrm{S}$ cannot be rejected. Finally, the Mo-Fe distance of $2.72 \AA$ is close to the value of $2.76 \AA$ observed in $\left(\eta^{5}-\mathrm{C}_{5} \mathrm{H}_{5}\right)_{3} \mathrm{Mo}_{3}-$ $\mathrm{FeS}_{4} \mathrm{Br}^{39}$

The calculated numbers and distances of sulfurs and irons appear chemically reasonable, and they may be interpreted through comparison with known structures as representing three or four bridging sulfides, one or two terminal cysteine sulfurs, and two or three sulfido-bridged irons. With this interpretation, at least two distinct models for the nitrogenase Mo site may be proposed (I and II).

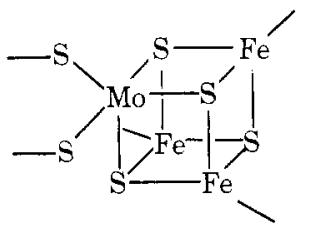

I

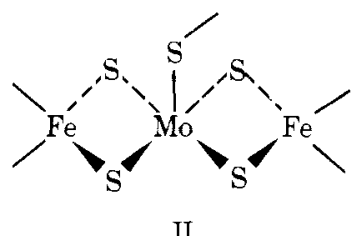

II
The essential feature of both of these models is the proximity of iron, bridged by sulfur, to molybdenum, with an extra ligand(s) (perhaps cysteine) on the Mo. Both of these models satisfy all of the constraints of the current absorption edge and EXAFS information, and each has its own special appeal. The
Mo- $\mathrm{Fe}-\mathrm{S}$ cube ( $\mathrm{I}$ ) is a variation on well-known $4 \mathrm{Fe}-4 \mathrm{~S}$ clusters, and inorganic clusters containing molybdenum and iron have been prepared and crystallographically characterized ${ }^{39}$ (unfortunately these structures contain $3 \mathrm{Mo}-1 \mathrm{Fe}$ rather than $1 \mathrm{Mo}-3 \mathrm{Fe}$ ). A bridging structure similar to Il has been proposed for $\left[\left(\mathrm{MoS}_{4}\right)_{2} \mathrm{Fe}\right]^{2-}, 40$ but the latter compound also has an inverted $\mathrm{Fe}-\mathrm{Mo}$ ratio.

It is tempting to envision $\mathrm{N}_{2}$ interactions simultaneously with both the Mo and $\mathrm{Fe}$ in these structures, or modifications thereof. However, it should be emphasized that none of the current data can address the problem of the site of $\mathrm{N}_{2}$ reduction. Furthermore, although both of these models involve five-coordinate $\mathrm{Mo}$, the data cannot rule out a six-coordinate species. A single nitrogen or oxygen ligand would probably be missed in the EXAFS, given the current signal to noise ratio. Alternatively, a set of several cysteine ligands with a wide spread in Mo-S bond lengths would yield a deceptively weak contribution to the EXAFS. Therefore, further experiments are necessary to test for coordinative unsaturation of the Mo site.

\section{Summary}

$\mathrm{X}$-ray absorption spectroscopy has proven to be a useful tool for study of the Mo site in nitrogenase. The combined absorption edge and EXAFS data are indicative of primarily sulfur ligation, and curve-fitting analysis of the fine structure indicates the existence of a Mo-Fe-S cluster. Although the limited sensitivity of this technique necessitates the use of very concentrated samples, $\mathrm{x}$-ray absorption spectroscopy is at present the only spectroscopic method for unambiguously observing the Mo under various conditions. Future experiments using $\mathrm{CO}, \mathrm{N}_{2}, \mathrm{C}_{2} \mathrm{H}_{2}$, and $\mathrm{Ar}$ atmospheres may help clarify the nature of the small molecule interaction site(s) in this protein. Collection of extended fine structure data on the fully reduced and dye-oxidized states could help determine whether the $\mathrm{Mo}-\mathrm{Fe}-\mathrm{S}$ species is involved in the EPR-observed oxidation level changes. Furthermore, examination of the Fe edges in $\mathrm{Fe}-\mathrm{Mo}$ cofactor, demolybdo component I, and intact $\mathrm{MoFe}$ protein under various conditions will yield information about the types of $\mathrm{Fe}$ present and their role in the catalytic process. The availability of powerful synchrotron radiation sources has opened a new spectroscopic window on nitrogenase and metalloproteins in general, and a wide range of novel experiments is now accessible.

Acknowledgments. We would like to thank Sebastian Doniach for helpful discussions concerning EXAFS analysis. We would also like to acknowledge Tom Eccles for the computer programming of both data collection and data analysis packages and Herman Winick and the members of the Stanford Synchrotron Radiation Laboratory (SSRL) staff for their technical assistance in support of this project. K. O. Hodgson is a Fellow of the Alfred P. Sloan Foundation and S. P. Cramer was an IBM Doctoral Fellow for 1976-1977. This work was supported by the National Science Foundation through Grant PCM-75-17105 and through Grant GB-22629 (Mortenson). Synchrotron Radiation time was provided by SSRL, supported by the National Science Foundation Grant DMR-07692-A02 in cooperation with the Stanford Linear Acceleration Center and the Energy Research and Development Administration.

\section{References and Notes}

(1) (a) Stanford University; (b) Purdue University.

(2) (a) T. C. Huang, W. G. Zumft, and L. E. Mortenson, J. Bacteriol., 113, 884 (1973); (b) R. W. Hardy, R. C. Burns, and G. W. Parshall in "Inorganic Biochemistry", G. L. Eichhorn, Ed., Elsevier, Amsterdam, 1973, pp 745793.

(3) R. R. Eady, B. E. Smith, K. A. Gook, and J. R. Postgate, Biochem. J., 128, 655 (1972).

(4) (a) J. S. Chen, J. S. Multani, and L. E. Mortenson, Biochim. Biophys. Acta 310,51 (1973). (b) The magnetic circular dichroism of the semireduced 
MoFe protein from 600 to $350 \mathrm{~nm}$ is slightly positive and monotonically increasing - unpublished results of the authors with Dr. John Dawson.

(5) G. Palmer, J. S. Multani, W. C. Cretney, W. G. Zumft, and L. E. Mortenson, Arch. Biochem. Biophys., 153, 325 (1972).

(6) B. E. Smith, D. J. Lowe, and R. C. Bray, Biochem. J., 135, 331 (1973)

(7) W. H. Orme-Johnson and L. C. Davis in "Iron-Sulfur Proteins", Vol, 3, W. Lovenberg, Ed., Academic Press, New York, N.Y., 1977, p 31.

(8) As the authors of ref 7 have noted, the Mo might be present in an EPR-active structure with insufficient spin density localized on the metal for observation of the electron-nucleus interaction

(9) Even the number of Mo atoms necessary for a functional MoFe molecule is still in some doubt (ref 7, p 25). The nutritional requirement is clearly necessary but not sufficient evidence for the involvement of Mo in nitrogenase.

(10) (a) R. G. Shulman, P. Eisenberger, W. E. Blumberg, and N. A. Stombaugh, Proc. Natl. Acad. Sci. U.S.A., 72, 4003 (1975); (b) P. Eisenberger, R. G. Shulmann, G. S. Brown, and S. Ogawa, ibid., 73, 491 (1976).

(11) (a) V. W. Hu, S. I. Chan, and G. S. Brown, Proc. Natl. Acad. Sci. U.S.A., 74, 3921 (1977); (b) T. K. Eccles, Ph.D. Thesis, Stanford University, 1977.

(12) S. P. Cramer, T. K. Eccles, F. Kutzler, K. O. Hodgson, and L. E. Mortenson, J. Am. Chem. Soc., 98, 1287 (1976).

(13) Throughout this paper, we refer to oxo groups tightly bound to molybdenum, whose short (1.6-1.8 $\AA$ ) Mo-O bond lengths are indicative of multiple bonding, as "doubly bound" oxygens.

(14) W. G. Zumft and L. E. Mortenson, Eur. J. Biochem., 35, 401 (1973).

(15) M. Walker and L. E. Mortenson, J. Biol. Chem., 249, 6356 (1973).

(16) W. G. Zumft, L. E. Mortenson, and G. Palmer, Eur. J. Biochem., 46, 525 (1974).

(17) L. E. Mortenson, W. G. Zumft, and G. Palmer, Biochim. Biophys. Acta, 292, 422 (1973).

(18) W. G. Zumft and L. E. Mortenson, Biochim. Biophys. Acta, 416, 1 (1975).

(19) B. M. Kincaid, Ph.D. Thesis, Stanford University, 1974

(20) J. A. Bearden, Rev. Mod. Phys., 39, $78(1967)$

(21) S. P. Cramer, K. O. Hodgson, E. I. Stiefel, and William E. Newton, J. Am. Chem. Soc., 100, 2748 (1978)

(22) S. P. Cramer, K. O. Hodgson, and E. I. Stiefel, manuscript in preparation.

(23) For a review of absorption edge spectroscopy prior to synchrotron radiation developments, see U. C. Srivastava and H. L. Nigam, Coord. Chem. Rev., 9, 275 (1973).

(24) R. G. Shulman, Y. Yafet, P. Eisenberger, and W. E. Blumberg, Proc. Natl. Acad. Sci. U.S.A., 73, 1384 (1976).

(25) S. P. Cramer, Ph.D. Thesis, Stanford University, 1977, Chapter 6

(26) For lack of suitable all-N complex data, we present data on Mo chlorides. Since the electronegativity of nitrogen is between that of chlorine and oxygen, Mo-N complexes should exhibit edges intermediate to the chloride and oxide edges, for a given metal oxidation state.

(27) Appellations such as $1 \mathrm{~s}-3 \mathrm{~d}$ and $1 \mathrm{~s}-4 \mathrm{~s}$ are to some extent misleading, since it is the very fact that the final state is a mixed state with some $p$ character which makes these transitions allowed. The terms are useful in designating the predominant character of the final state, however.

(28) Measurement of the Mo edge inflection point of a dilute sample is subject to an extra source of error because of the protein background absorption, which was almost $99 \%$ of the total absorption $(A)$ for the solution experiments. The inflection point $E_{\text {inf }}$ is defined as the energy at which the second derivative $\mathrm{d}^{2} A / \mathrm{d} E^{2}=0$. If the protein background were a linear function of energy, $A_{\text {back }}=a+b E$, its second derivative would be zero and it would not affect the measured inflection point. However, in practice the protein background is a decreasing signal with positive curvature: $A_{\text {back }}=a+b E$ $\left.+c E^{2}, b<0, c\right\rangle 0$. The positive background curvature will shift the observed inflection poit to higher energies as the sample becomes more dilute. It would thus be desirable to repeat these edges with protein samples of exactly the same Mo concentration.

(29) It should be noted here that the air-oxidized edges reported here are essentially the same as the edge previously reported for "resting-state" nitrogenase (ref 12). It now appears that so-called "resting-state" nitrogenase was permanently at rest, that is, irreversibly air oxidized.

(30) E. A. Stern, D. E. Sayers, and F. W. Lytle, Phys. Rev. Sect. B, 11, 4836 (1975).

(31) We note here that the EXAFS Fourier transform abscissa, labeled " $R$ ", is $0.5 \times$ the mathematical transform dimension; thus the frequency difference observed in the transform is one-half the difference observed by direct analysis of the EXAFS in $k$ space.

(32) In structures such as metalloporphyrins and pure metals, which contain highly symmetric sheils of atoms around the absorbing atom, EXAFS components for atoms as far as $5 \AA$ are easily observed. However, for most of the Mo compounds studied in ref 21, atoms without a bonding interaction with Mo were not easily seen.

(33) The Mo-Fe phase shift, $\alpha_{M 0-F e}$, was calculated as the sum of (1) the theoretical Fe scatterer phase shift and (2) the average difference between empirical Mo-C, Mo-O, and Mo-S and theoretical $C, O$, and $S$ phase shifts. We are, therefore, using the fact that $\alpha_{\text {Mo-Fs }}=\alpha_{\mathrm{Fa}_{\mathrm{B}}}$ (calcd) $+\left[\alpha_{\mathrm{Mo}-\mathrm{x}}\right.$ (empirical) $-\alpha_{x}$ (calcd)], where the quantity in brackets is the average difference between empirical pairwise phase shifts and calculated scatterer phase shifts. The theoretical phase shifts were taken from ref 34 , while the procedure for using relationships between phase shifts is a modification of that in ref 35 . Since we do not know the shape or magnitude of the MoFe amplitude function, we have assumed that it will be similar to the Mo-S amplitude, only larger by a factor of $Z_{\mathrm{Fe}} / Z_{\mathrm{S}}$ or $26 / 16$. The approximately linear $Z$ dependence of EXAFS amplitudes is discussed in ref 21.

(34) P. A. Lee, B. K. Teo, and A. L. Simons, J. Am. Chem. Soc., 99, 3856 (1977)

(35) P. H. Citrin, P. Eisenberger, and B. M. Kincaid, Phys. Rev. Lett., 36, 1346 (1976).

(36) The long Mo-O bond length of $2.30 \AA$ in the oxo-bridged molybdenum cysteine dimer has been attributed to ligand constraints and a MO=O trans effect.

(37) (a) E. I: Stiefel and J. K. Gardner, "Proceeding of the First International Conference on the Chemistry and Uses of Molybdenum", P. C. H. Mitchell, Ed., London, 1973, pp 272-277; (b) R. J. P. Williams and R. A. D. Wentworth, ibid., pp 212-215; (c) R. W. F. Hardy and E. Knight. Jr., Prog. Phy tochem., 1, 212-215 (1968); (d) G. W. Parshall, J. Am. Chem. Soc., 89 1822 (1967)

(38) (a) E. Stern, Phys. Rev. Sect. B, 10, 3027 (1974); (b) C. A. Ashley and S Doniach, ibid., 11, $1279(1975)$.

(39) L. Dahl, private communication.

(40) E. Diemann and A. Mueller, Coord. Chem, Rev., 10, 79 (1973).

\title{
Allylic Alkylation: Preparation of $\pi$-Allylpalladium Complexes from Olefins
}

\author{
Barry M. Trost,* Paul E. Strege, Lothar Weber, \\ Terry J. Fullerton, and Thomas J. Dietsche \\ Contribution from the Department of Chemistry, University of Wisconsin, \\ Wisconsin 53706. Received October 20, 1977
}

\begin{abstract}
Allylic alkylation requires activation of the allylic $\mathrm{C}-\mathrm{H}$ bond and formation of a $\mathrm{C}-\mathrm{C}$ bond. A mild way for achieving this activation is developed. A general procedure to obtain $\pi$-allylpalladium complexes from simple and complex olefins in good yields is described. The regio- and chemoselectivity is examined. A mechanistic rationale is put forth.
\end{abstract}

The advent of the Wacker process initiated a flood of activity in organopalladium chemistry. ${ }^{1}$ In studying the mechanism of this reaction, the possibility that $\pi$-allylpalladium complexes could be formed as by-products leading to allylic oxidation was noted. The possibility that organometallic reagents could be directly available from olefins under mild conditions attracted our attention as a route to allylic alkylation. Specifically, we became concerned with the problem outlined in eq 1 , the ability to replace an allylic $\mathrm{C}-\mathrm{H}$ bond with

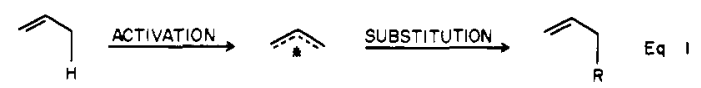

an allylic $\mathrm{C}-\mathrm{C}$ bond. Such a process can be envisioned to involve two stages, activation followed by substitution. Indeed, allylic halogenation followed by coupling with an organometallic such as a cuprate constitutes such a process. Lithiation followed by coupling with an alkylating agent or a carbonyl compound also constitutes a reasonable approach. These ap- 